American Journal of Environmental Sciences 4 (5): 522-534, 2008

ISSN 1553-345X

(C) 2008 Science Publications

\title{
Environmental Impact Assessment for Potential Continuous Processes for the Production of Carbon Nanotubes
}

\author{
${ }^{1}$ Aditi Singh, ${ }^{1}$ Helen H. Lou, ${ }^{2}$ Ralph W. Pike, ${ }^{2}$ Adedeji Agboola, ${ }^{1}$ Xiang Li \\ ${ }^{1}$ Jack R. Hopper and ${ }^{1}$ Carl L. Yaws \\ ${ }^{1}$ Department of Chemical Engineering, Lamar University, P.O. Box 10053, Beaumont, TX 77710 \\ ${ }^{2}$ Department of Chemical Engineering, Louisiana State University \\ 110 Chemical Engineering Bldg., Baton Rouge LA 70803
}

\begin{abstract}
As an emerging discipline, nanotechnology has the potential to improve environmental sustainability through its application in pollution prevention, treatment, remediation, etc. One challenging issue in the growth of nanotechnology is how to produce purified carbon nanotubes (CNT) in commercial quantities at affordable price and with low environmental impacts. A detailed assessment of such a manufacturing process from both economic and environmental aspects at the design phase will benefit both the industry and the society. In this work, an LCA type of environmental impact assessment is conducted for the conceptual design of two catalytic, chemical vapor deposition processes (CNT-PFR and CNT-FBR) used for continuous large-scale production of CNT. The core of both processes is a high-temperature catalytic reactor. Mineral acids are used in the purification steps, from which liquid and solid wastes are generated and must be treated before discharge. Based on the simulation results, the environmental impacts of each process are calculated. The results provide vital information that can be used during the design phase of these processes for better decision-making.
\end{abstract}

Key words: LCA, carbon nanotube, process design, environmental impacts

\section{INTRODUCTION}

Carbon nano-tubes (CNT) are single atom layers of carbon rolled up into tubes with nano-scale diameter. They have wide variety of applications ranging from manufacturing composite fibers for better thermal, electrical and mechanical properties to several varied applications in electronics and optics ${ }^{[1]}$.

Popular techniques used to manufacture CNT include arc-discharge, laser ablation, using high pressure carbon monoxide and chemical vapor deposition. An extensive literature review was conducted by Agboola ${ }^{[1]}$, which included information about the reactor type, dimensions, energy requirements, operating conditions, reactants, products, catalysts, conversion, carbon nanotube yield, selectivity as well as purification techniques employed in experimental studies for each process. The candidate production processes were selected from these processes for further analysis on the basis of their capital and operating cost, raw materials selection, operation mode, production/purification methods, and process operating conditions. The details of this selection process can be found in Agboola, $2005^{[1]}$.
On the basis of this criteria, two processes were selected to conduct an environmental assessment, the high-pressure carbon monoxide disproportionation in a plug-flow reactor (CNT-PFR) and the cobaltmolybdenum fluidized bed catalytic reactor (CNTFBR) were selected for the conceptual design. The CNT-PFR reactor has catalytic particles formed in situ by thermal decomposition of iron carbonyl. The CNTFBR process employs the synergistic effect between the cobalt and molybdenum to give high selectivity to carbon nanotubes from $\mathrm{CO}$ disproportionation.

In this work, an environmental impact analysis has been conducted to assess the performance of CNT-PFR process and CNT-FBR process in terms of their environmental sustainability. These results are expected to provide the manufacturer with more comprehensive data about each process for better decision-making. In this study, firstly details of the CNT-PFR process and CNT-FBR process are presented. After that, the natural resource consumption and output data for both these processes is discussed. Then, the impact assessment methodology is discussed followed by the results of the case study developed for the CNT-PFR and CNT-FBR processes.

Corresponding Author: Helen H. Lou, Department of Chemical Engineering, Lamar University, P.O. Box 10053, Beaumont TX 77710. Tel 409-880-8207; Fax: 409-880-2197 
Conceptual design of the CNT-PFR (HiPCO) process: This design is based on the high-pressure plug flow (PFR) reactor which converts carbon monoxide into single-wall carbon nanotubes and carbon dioxide, at high pressures (30-50 bar), and at temperatures between $1,273 \mathrm{~K}$ and $1,473 \mathrm{~K}$ from carbon monoxide and iron pentacarbonyl catalyst precursor. The overall conversion of carbon monoxide to carbon nanotubes in the CNT-PFR reactor was $20 \mathrm{~mol} \%{ }^{[2]}$. The process flow diagram for this process is illustrated in Fig. 1. The mass flow rates given in the diagram are in $\mathrm{kg} / \mathrm{hr}$. A detailed description of each process unit can be found in Agboola, 2005 $5^{[1]}$.

The CNT-PFR process for carbon nanotubes production can be divided into four sections: feed preparation section, the reactor section, the separation/purification section and the absorber section. Next, a brief description of each section is given.

Feed preparation section: The process equipment used in this section includes a mixer (V-101), a gasfired heater (E-101) and a gas compressor $(\mathrm{C}-101)$. The gas streams entering the mixer consist of fresh carbon monoxide (CO) at mass flow rate of $2,637 \mathrm{~kg} / \mathrm{hr}$ and iron pentacarbonyl vapor $\left(\mathrm{Fe}(\mathrm{CO})_{5}\right)$ at $627 \mathrm{~kg} / \mathrm{hr}$. The mixer blends them together at $303 \mathrm{~K}$. The gas stream leaving the mixer is sent to the flow reactor $(\mathrm{V}-$ $102)$ at $303 \mathrm{~K}$ and atmospheric pressure. The unconverted $\mathrm{CO}$ is completely recovered and recycled back in the reactor from the compressor. The $\mathrm{CO}$ recycle stream passes through two heat exchanger units successively, the cross heat exchanger and the gas-fired heater which increases its temperature to $1,323 \mathrm{~K}$, the required feed temperature for the reactor.

Reactor section: The process units used in this section include a high-pressure reactor $(\mathrm{V}-102)$, a gas-solid filter (Z-101), the reactor effluent-feed recycle cross heat exchanger (E-102), the waste heat boiler (E-103), and the heat exchanger water cooler (E-104). The mixed gas stream containing $\mathrm{CO}$ saturated with iron pentacarbonyl vapor, and the $\mathrm{CO}$ recycle stream from the heater are passed through the flow reactor $(\mathrm{V}-102)$. The flow reactor is modeled as an isothermal plug-flow reactor at 450 psia and $1,323 \mathrm{~K}$, based on laboratory experiments ${ }^{[3]}$. Upon heating, the iron pentacarbonyl vapor decomposes to iron atoms and $\mathrm{CO}$ according to following equation:

$$
\mathrm{Fe}(\mathrm{CO})_{5} \stackrel{\text { Heat }}{\longrightarrow} \mathrm{Fe}_{(s)}+5 \mathrm{CO}_{(g)}
$$

The iron formed from the decomposition of the iron pentacarbonyl, nucleates and forms iron clusters that initiate the growth of carbon nanotubes in the gas phase by carbon monoxide disproportionation exothermic reaction (Boudouard reaction):

$$
\begin{aligned}
& x(\mathrm{CO})_{(g)} \stackrel{F e}{\longrightarrow} C N T_{(s)}+\frac{x}{2} C O_{2(g)} \\
& \Delta \mathrm{H}=-172.5 \mathrm{~kJ} / \mathrm{kgmol}
\end{aligned}
$$

$$
2(\mathrm{CO})_{(g)} \stackrel{F e}{\longrightarrow} C_{(s)}+\mathrm{CO}_{2(g)}
$$

In this design, the conversion of $\mathrm{CO}$ in the flow reactor to form carbon nanotube is $20 \mathrm{~mol} \%$, based on the optimal conversion obtained in the laboratory-scale HiPCO reactor ${ }^{[4]}$. The selectivity of $\mathrm{CO}$ forming carbon nanotubes is $90 \%$ and the selectivity of CO forming amorphous carbon is $10 \%$, based on high TEM studies $^{[2]}$. The effluent stream from the reactor contains carbon nanotube (CNT), amorphous carbon, iron particles, $\mathrm{CO} 2$ and unconverted $\mathrm{CO}$. This stream is sent to a gas-solid filter which separates the solid products containing carbon nanotube, residual iron and amorphous carbon from the hot, mixed carbon monoxide and carbon dioxide gas stream. The hot mixed-gas stream is used to preheat the $\mathrm{CO}$ recycle stream in the cross heat exchanger. It is then passed to the waste heat boiler that cools the mixed gas stream while producing saturated steam from boiler feed water(BFW). The gas stream is further cooled using cooling water and fed into the gas absorption column $(\mathrm{T}-101)$ as bottoms at $330 \mathrm{~K}$.

Separation/purification section: The process units used in the separation/purification section include the previously described gas-solid filter (Z-101), an air oxidizer (V-103), an acid treatment tank (V-104), a liquid-solid filter (Z-102), a product drier (Z-103), an acid regeneration column (Z-104) and a centrifuge separator $(\mathrm{Z}-106)$. These process units are used to separate and purify the carbon nanotube product from impurities such as amorphous carbon and iron nanoparticles. The purification process in the CNT-PFR process involves a multi-step approach: oxidation, acid treatment, filtration and drying. In the oxidizer, hot air gas stream is passed over the carbon nanotube product collected from the filter to selectively remove amorphous carbon impurities and oxidize the iron particles to iron oxide ${ }^{[5]}$. The oxidized carbon nanotube product containing iron oxides is treated with $12 \%$ hydrochloric acid $(\mathrm{HCl})$ solution in the acid treatment $\operatorname{tank}^{[6]}$. This removes the remaining iron particles embedded in nanotubes in the form of iron (II) chloride $\left(\mathrm{FeCl}_{2}\right)$. The final carbon nanotube product contains 97 mol\% carbon nanotubes and $3 \mathrm{~mol} \%$ iron $^{[2]}$. The nanotube slurry, containing the dissolved iron chloride, and carbon nanotube is sent to the liquid-solid filter, 
Am. J. Environ. Sci., 4 (5): 522-534, 2008

which separates the purified carbon nanotubes from the iron chloride solution. The carbon nanotubes collected are washed several times with deionized water and then filtered, purified and dried in the product drier. The iron chloride solution is sent to an acid regeneration column where the hydrochloric acid solution is regenerated.

Absorber section: The process units in the absorber section include a gas absorber (T-101), a gas stripping column (T-102), and a cross heat exchanger (E-105). Other process units include a kettle reboiler (E-106), a flash drum (V-105) and a discharge/vent valve (Z105). The carbon dioxide produced during the $\mathrm{CO}$ disproportionation reaction over catalytic iron nanoparticles is absorbed in the counter-current flow of monoethanol amine (MEA) solution in the gas absorption column. The unconverted $\mathrm{CO}$ is recovered and recycled back to the reactor. The $\mathrm{CO}_{2}$-rich MEA solution leaves the gas absorption column from the bottom and enters the solute rich-lean solvent cross heat exchanger which preheats the $\mathrm{CO}_{2}$-rich MEA solution. Carbon dioxide gas is stripped from the solute-rich MEA solution in the column by steam stripping. The gas stripped from the stripping column is sent to the flash drum, where the carbon dioxide gas stream and water vapor are separated.

Natural resource consumption data for CNT-PFR process: This section provides the natural resource consumption data for CNT-PFR process. It is expressed in terms of total amount of natural gas, water, air and coal consumed for the production of $595 \mathrm{~kg} / \mathrm{hr}$ of 97 mol \% pure CNT.

Water: The total amount of water used in the CNTPFR process is in form of raw material in acid regeneration column (Z-104) and utilities (CW, BFW and Steam). The HP steam is used in kettle-reboiler (E106), reactor (V-102) and the product drier (Z-103). The total amount of HP Steam consumed is $4439 \mathrm{~kg} / \mathrm{hr}$. Apart from this, water is also used for cooling in the form of cooling water and boiler feed water (E-104, V103, E-103). This adds up to $59545 \mathrm{~kg} / \mathrm{hr}$ of water. Water is also used in the acid regeneration column at the rate of $255 \mathrm{~kg} / \mathrm{hr}$. This adds up to a total consumption of $64239 \mathrm{~kg}$ of water per hour. The details of total water consumption are tabulated in Table 1.

Natural gas: Natural gas is used to heat the gas fired heater (E-101). It is also assumed to be used as fuel for producing HP steam, and for providing $809288 \mathrm{~kJ} / \mathrm{hr}$ to the gas stripping column (T-102). In order to calculate the total consumption of natural gas, it is assumed that
Table 1: Total water consumed in CNT-PFR process

\begin{tabular}{llr}
\hline Unit & Material & Flow Rate $(\mathrm{Kg} / \mathrm{hr})$ \\
\hline E-103 & BFW & 6517 \\
E-104 & CW & 52522 \\
V-103 & CW & 506 \\
E-106 & HP Steam & 2565 \\
V-102 & HP Steam & 1482 \\
Z-103 & HP Steam & 392 \\
Z-104 & H2O & 255 \\
& Total Water & 64239 \\
\hline
\end{tabular}

Table 2: Total amount of natural gas consumed for HP steam production in CNT-PFR process

\begin{tabular}{lllc}
\hline Unit & & Flow Rate $(\mathrm{Kg} / \mathrm{hr})$ & Heat Provided $(\mathrm{Kj} / \mathrm{hr})$ \\
\hline E-106 & HP Steam & 2565 & 4261155 \\
V-102 & HP Steam & 1482 & 2462606 \\
Z-103 & HP Steam & 392 & 650984 \\
& Net HP & 4439 & 7374745 \\
& & Equipment Efficiency (75\%) & 9832993 \\
& & Boiler Efficiency (65\%) & 15127682 \\
& & NG Used (kg/hr) & 272.56 \\
\hline
\end{tabular}

Table 3: Total natural gas consumed in CNT-PFR process

\begin{tabular}{llc}
\hline Unit & Material & Flow Rate $(\mathrm{Kg} / \mathrm{hr})$ \\
\hline E-101 & NG & 486 \\
E-106 & HP Steam & \\
V-102 & HP Steam & \\
Z-103 & HP Steam & 272.56 \\
T-102 & NG & 19.44 \\
& Total NG Used & 778 \\
\hline
\end{tabular}

Table 4: Total amount of air consumed in CNT-PFR process

\begin{tabular}{llc}
\hline Unit & Material & Flow Rate $(\mathrm{Kg} / \mathrm{hr})$ \\
\hline $\mathrm{V}-103$ & $\mathrm{O}_{2}$ & 176 \\
$\mathrm{Z}-104$ & $\mathrm{O}_{2}$ & 26 \\
& Total $\mathrm{O}_{2}$ & 202 \\
& Total Air & 1058 \\
\hline
\end{tabular}

the heat transfer efficiency of each equipment is $75 \%$ and the heat transfer efficiency of the boiler used for steam production is $65 \%$. A back calculation gives the total amount of natural gas used for the production of HP steam as $272.56 \mathrm{~kg} / \mathrm{hr}$ (Table 2). The total amount of natural gas used in the CNT -PFR process is 778 $\mathrm{kg} / \mathrm{hr}$ (Table 3). The value of heat of combustion of natural gas used for these calculations is $55501.2 \mathrm{~kJ} / \mathrm{hr}$.

Air: Air is consumed directly in air oxidizer (V-103) as a source of oxygen. Moreover, the acid regeneration tank also uses some oxygen. Although both streams contain $100 \%$ oxygen, it is assumed that this oxygen is obtained from air and air is used $10 \%$ in excess. Thus, a back calculation by assuming air has $21 \%$ oxygen gives the total amount of air used as $1058 \mathrm{~kg} / \mathrm{hr}$ (Table 4).

Coal: The gas compressor (C-101) uses $1056 \mathrm{~kW}$ of electricity. It is assumed that the fuel used for the production of electricity is coal. Using the conversion 
Am. J. Environ. Sci., 4 (5): 522-534, 2008

Table 5: Total carbon dioxide produced by CNT-PFR process

\begin{tabular}{llc}
\hline Stream & Components & Flow Rate $(\mathrm{kg} / \mathrm{hr})$ \\
\hline ARout & $\mathrm{CO}_{2}$ & 242 \\
SR27 & $\mathrm{CO}_{2}$ & 2424 \\
& Total CO & 2666 \\
\hline
\end{tabular}

Table 6: Total water consumed in CNT-FBR process

\begin{tabular}{llc}
\hline \multicolumn{2}{l}{ Total Water Consumption } & \\
\hline Unit & Material & Flow Rate $(\mathrm{Kg} / \mathrm{hr})$ \\
\hline Z-207 & HP Steam & 223 \\
V-201 & HP Steam & 2168 \\
Z-206 & HP Steam & 392 \\
E-205 & HP Steam & 2885 \\
Z-208 & H2O (l) & 265 \\
E-202 & BFW & 59089 \\
E-203 & CW5 & 7333 \\
& Total Water & 72355 \\
\hline
\end{tabular}

factor $(1 \mathrm{~kW}$-h of electricity $=10000 \mathrm{Btu}$ fuel in power plant), the total amount of coal used on an hourly basis for providing power to the compressor is calculated as $40.109 \times 10^{6} \mathrm{MJ}$.

Emissions/discharge data for CNT-PFR process: The CNT-PFR process produces carbon nanotubes with trace amounts of iron (II) chloride $\left(\mathrm{FeCl}_{2}\right)$ as impurity. This impurity is treated as a part of the final product. Since the scope of the impact assessment conducted in this study is only from "Entry-to-Exit", it does not include the usage and disposal phase of the carbon nanotubes produced by CNT-PFR process. Due to this, the $\mathrm{FeCl}_{2}$ in the $\mathrm{CNT}$ is treated as a part of the final saleable product. Apart from these, the process produces carbon dioxide, water and iron (III) oxide. This section provides a brief description about these emissions. Since the scope of this study is "Entry-toExit", we do not treat $\mathrm{FeCl}_{2}$ as an emission to the environment. It is treated as a part of the final saleable product. Other chemicals emitted from the process are listed below.

Carbon dioxide $\left(\mathbf{C O}_{2}\right)$ : Total $\mathrm{CO}_{2}$ released by CNTPFR process is $2666 \mathrm{~kg} / \mathrm{hr}$ (Table 5). When released in the atmosphere, pure $\mathrm{CO}_{2}$ traps outgoing long wave radiation and adds to global warming. This pure carbon dioxide generated by CNT-PFR process can be used as a raw material for other processes ${ }^{[7]}$. Thus, this carbon dioxide may either be released in the atmosphere as it is or can be reused as a resource by another process.

Ferric oxide $\left(\mathrm{Fe}_{2} \mathbf{O}_{3}\right)$ : The centrifuge (Z-106) produces $256 \mathrm{~kg} / \mathrm{hr}$ of $\mathrm{Fe}_{2} \mathrm{O}_{3}$. It is a reddish-brown powder which has less than $1 \%$ solubility in water. This can be either disposed in a land-fill site or sold as a by product to be used as a raw material. $\mathrm{Fe}_{2} \mathrm{O}_{3}$ can be used for
Table 7: Total natural gas consumed in CNT-FBR process for HP steam production

\begin{tabular}{lllc}
\hline Unit & & Flow Rate $(\mathrm{kg} / \mathrm{hr})$ & Heat provided $(\mathrm{Kj} / \mathrm{hr})$ \\
\hline V-201 & HP Steam & 2168 & 3602442 \\
Z-206 & HP Steam & 392 & 650984 \\
E-205 & HP Steam & 2885 & 4792884 \\
Z-207 & HP Steam & 223 & 370125 \\
& Net HP & 5668 & 9416435 \\
& & Equipment Efficiency (75\%) & 12555247 \\
& & Boiler Efficiency (65\%) & 19315764 \\
& & NG Used (kg/hr) & 348.02 \\
\hline
\end{tabular}

Table 8: Total natural gas consumed in CNT-FBR process

\begin{tabular}{llc}
\hline Unit & Material & Flow Rate $(\mathrm{Kg} / \mathrm{hr})$ \\
\hline E-201 & NG & 616 \\
V-201 & HP Steam & \\
Z-207 & HP Steam & \\
Z-206 & HP Steam & \\
E-205 & HP Steam & 348.02 \\
T-202 & NG & 16.40 \\
& Total NG Used & 980.42 \\
\hline
\end{tabular}

production of pure iron or as pigment for coloring in cosmetics and ceramic $^{[8]}$. The OSHA Permissible Exposure Limit (PEL) for Iron oxide fume is 10 $\mathrm{mg} / \mathrm{m}^{[3]}$.

Water $\left(\mathbf{H}_{2} \mathbf{O}\right)$ : The total amount of water released in this process depends upon how much water is being recycled. We can consider two different scenarios for this. In the first case, no water stream is recycled and all the water needs to be sent to a treatment facility before reuse. In that case the net output of water will be the same as input, $64239 \mathrm{~kg} / \mathrm{hr}$. Another possibility is that all the water is recycled. Since the water coming out of the product drier (Z-103) is pure, even that is recycled back to the acid-regeneration column. In this case, the amount of water dumped would be $0 \mathrm{~kg} / \mathrm{hr}$. This however, does not account for water losses of any kind during the steam cycle or in any other equipment.

Conceptual design of the CNT-FBR process: This design is based on carbon monoxide disproportionation over silica supported cobalt-molybdenum catalyst in a fluidized bed reactor. The reaction forms carbon nanotubes and carbon dioxide at temperatures between $973 \mathrm{~K}$ and $1,223 \mathrm{~K}$, and total pressure ranges from 15 psia to 150 psia. The conversion of $\mathrm{CO}$ in this process is $20 \mathrm{~mol} \%$ and its selectivity is $80 \%{ }^{[9]}$. The process flow diagram for the CNT-FBR process is shown in Fig. 2 where all the mass flow rates are in $\mathrm{kg} / \mathrm{hr}$. A detailed description of each process unit can be found in Agboola, 2005 ${ }^{[1]}$. The CNT-FBR process consists of the four sections: the feed preparation section, the reactor section, the absorber section and the separation/purification section. Next, a brief description of each section is provided. 
Am. J. Environ. Sci., 4 (5): 522-534, 2008

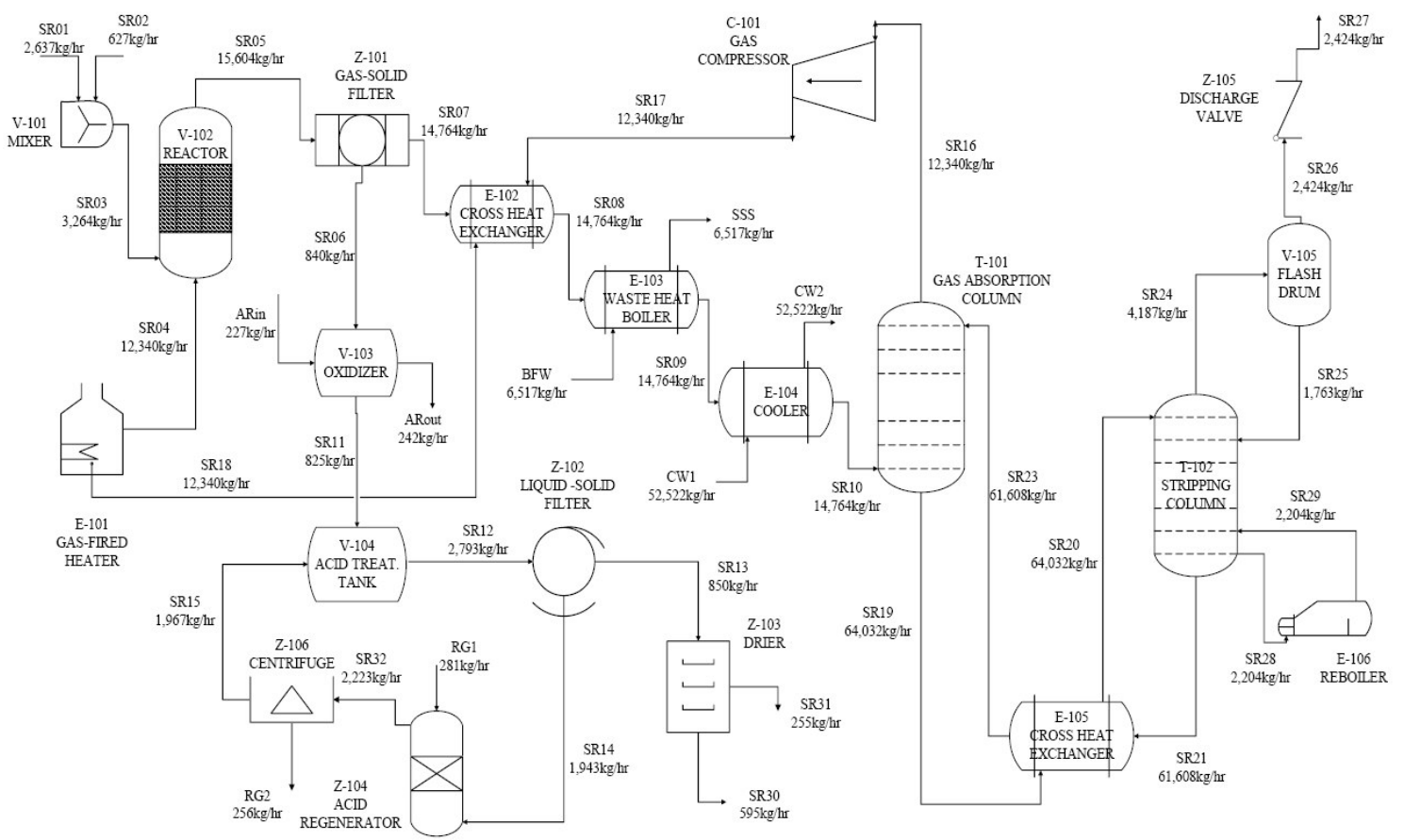

Fig.1: Process flow diagram for the CNT-PFR carbon nanot

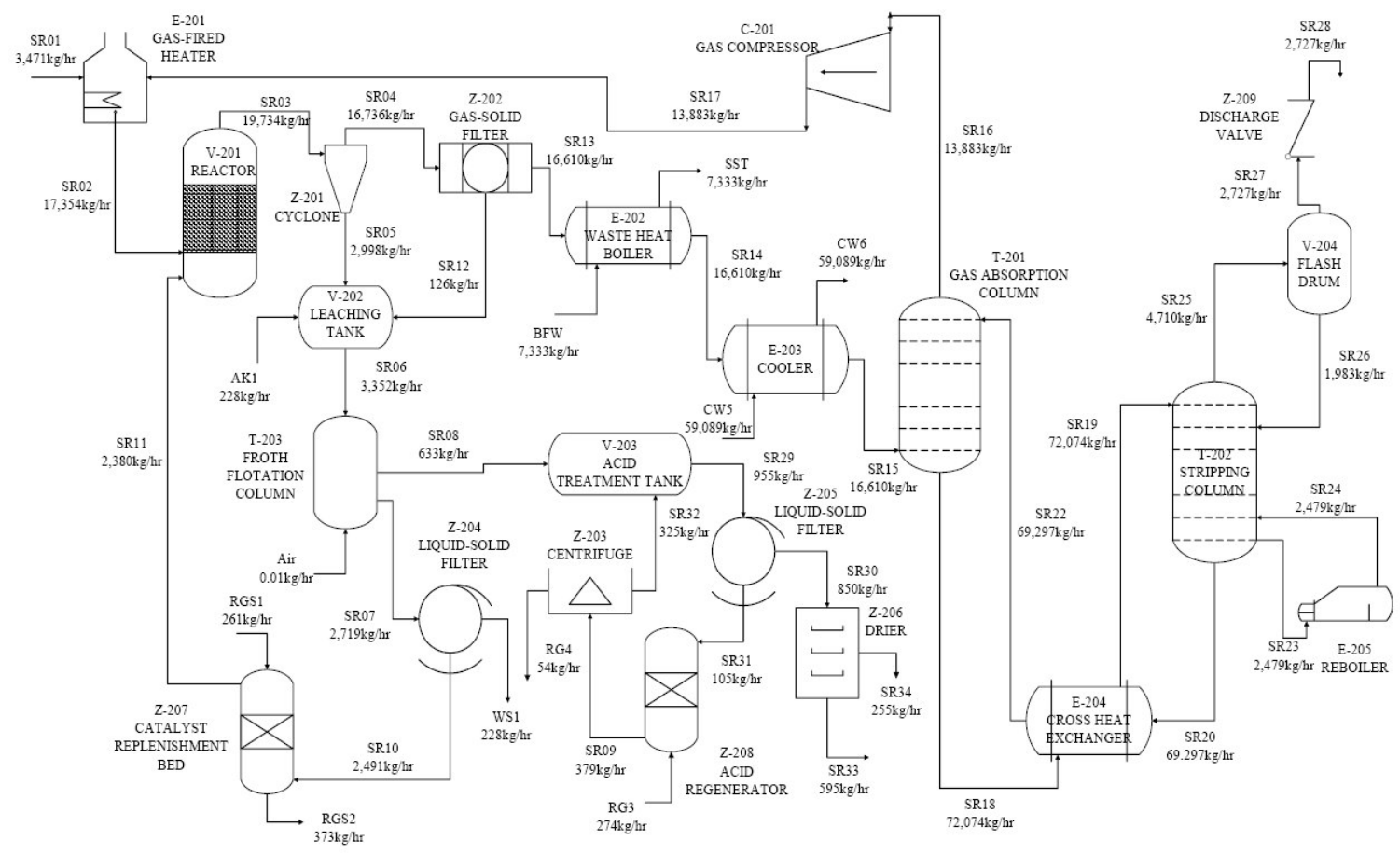

Fig. 2: Process flow diagram for the CNT-FBR carbon nanotube production process 
Feed preparation section: The process units in the feed preparation section include the heater $(E-201)$ and the gas compressor (C-201). The fresh feed of $\mathrm{CO}$ is combined with the $\mathrm{CO}$ recycle stream in the gas-fired heater. The combined $\mathrm{CO}$ feed stream is fed into the fluidized bed reactor at $1,223 \mathrm{~K}$ and $150 \mathrm{psia}$. The operating conditions in the reactor are maintained at $1,223 \mathrm{~K}$ and $150 \mathrm{psia}$, based on the experimental conditions in the laboratory-scale CNT-FBR process.

Reactor section: The reactor section consists of a fluidized bed reactor $(V-201)$, the cyclone separator (Z-201), the gas-solid filter (Z-202), the waste heat boiler (E-202) and the heat exchanger water cooler (E203). In the fluidized bed reactor, the $\mathrm{CO}$ feed stream is reacted on silica-supported cobalt-molybdenum catalysts at $1,223 \mathrm{~K}$ and $150 \mathrm{psia}$. Carbon nanotubes are formed by $\mathrm{CO}$ disproportionation over Co-Mo catalysts, according to the Boudouard reaction. The conversion of $\mathrm{CO}$ in the fluidized bed reactor to form carbon nanotube is $20 \mathrm{~mol} \%$. The selectivity of carbon monoxide to form carbon nanotubes with this reaction is $80 \%$ and to form amorphous carbon is $20 \%$. The effluent stream from the reactor contains carbon nanotubes, amorphous carbon, carbon dioxide and unconverted carbon monoxide. It is passed through a cyclone separator to separate the solid catalyst particles from the hot mixed-gas stream. The gas stream from the cyclone is passed through a gas-solid filter to remove any solid catalyst entrainments. The entrained solids are sent to the alkali leaching tank. The hot gas stream from the gas-solid filter is sent through a waste heat boiler which cools the mixed-gas stream while converting boiler feed water to saturated steam. The mixed-gas stream leaving the waste heat boiler is further cooled to $330 \mathrm{~K}$ using cooling water.

Separation/purification section: The carbon nanotubes produced in the fluidized bed reactor are grown on and remain attached to the silica-supported bimetallic catalysts. Froth flotation purification process is used to separate and purify the carbon nanotube using air as an inorganic solvent. The purity of carbon nanotubes produced by the froth flotation process is only $80 \%{ }^{[10]}$. Next, they are dissolved in $12 \%$ hydrochloric acid $(\mathrm{HCl})$ solution which improves the purity of the final nanotube product to $97 \mathrm{~mol} \% \mathrm{CNT}^{[9]}$. The silica-supported solid catalyst from the cyclone separator is sent to the alkali leaching tank, where it is washed with $2 \mathrm{M}$ sodium hydroxide solution. This solution breaks the carbon nanotubes-supported catalysts interaction by silica leaching without removing the cobalt-molybdenum metals present on the silica substrate. In the acid treatment tank, the residual cobalt and molybdenum catalysts react with hydrochloric acid solution to form soluble cobalt chloride and molybdenum chloride respectively. The carbon nanotube slurry is then passed through a liquidsolid filter which separates the purified carbon nanotube product from the liquid stream. The purity of the final carbon nanotubes product, obtained after acid dissolution and filtration, is $97 \mathrm{~mol} \%$ carbon nanotubes, $1.5 \mathrm{~mol} \%$ cobalt metal and $1.5 \mathrm{~mol} \%$ molybdenum metal particles ${ }^{[9]}$. The hydrochloric acid is recovered in an acid regeneration column from the oxidation of metal chlorides solution. The cobalt and molybdenum oxides produced in the acid regenerator are removed from the hydrochloric acid in the centrifuge separator. The recovered acid solution is subsequently recycled to the acid treatment tank.

Absorber section: After cooling, the outlet stream is sent to the absorber. The carbon dioxide in the feed is absorbed in the counter-current flow of MEA solution fed at the top of the absorption column. The unconverted $\mathrm{CO}$ gas stream is recycled to the reactor. The solute-rich MEA solution leaving the gas absorber at the bottom is passed to the solute-rich-lean solvent cross heat exchanger, where it is preheated by the lean MEA solution recovered from the stripping column in a cross heat exchanger. Carbon dioxide gas is stripped from the solute-rich solution in the gas stripper using saturated steam. The carbon dioxide leaves the stripping column from the top and is sent to the flash drum where any entrained liquid is recovered and returned to the gas stripping column.

Natural resource consumption data for CNT-FBR process: The following section presents the natural resource consumption data for CNT-FBR process. They are presented in terms of total water, natural gas, air and coal consumption.

Water: The total amount of water consumed in CNTFBR process is in the form of raw material in acid regeneration column (Z-208) and utilities $(\mathrm{CW}, \mathrm{BFW}$ and Steam). The total amount of water used for the production of HP steam used in kettle reboiler (E-205), reactor (V-201), the product drier (Z-206) and catalyst regeneration bed (Z-207) is $5668 \mathrm{~kg} / \mathrm{hr}$. Apart from this, $265 \mathrm{~kg} / \mathrm{hr}$ of fresh water is used in acid regeneration column (Z-208). Moreover, $59089 \mathrm{~kg} / \mathrm{hr}$ of boiler feed 
Am. J. Environ. Sci., 4 (5): 522-534, 2008

water is used in waste heat boiler (E-202) and 7333 $\mathrm{kg} / \mathrm{hr}$ of cooling water is used in heat exchanger water cooler (E-203). All these adds to a total consumption of $72355 \mathrm{~kg} / \mathrm{hr}$ of water (Table 6).

Natural gas: In the CNT-FBR process natural gas is used to heat the gas fired heater (E-201). It is assumed that natural gas is also used to produce the HP steam used in the process. Similar to CNT-PFR process, the heat transfer efficiency of each equipment is assumed to be $75 \%$ and that of a boiler is assumed to be $65 \%$. Using this data, it was found that the total amount of natural gas used for production of HP steam is 348.02 $\mathrm{kg} / \mathrm{hr}$ (Table7). The source of heat used to provide $910268 \mathrm{~kJ} / \mathrm{hr}$ of heat to the gas stripping column (T202) is assumed to be natural gas. A back calculation shows that the total amount of natural gas used in the CNT-FBR process is $980.42 \mathrm{Kg} / \mathrm{hr}$ (Table 8). The value of heat of combustion of natural gas used for these calculations is $55501.2 \mathrm{~kJ} / \mathrm{hr}$.

Air: Air is consumed directly in froth flotation column (T-203) as an inorganic solvent and in acid regeneration column (Z-208) as a source of oxygen. It is assumed that air is used $10 \%$ in excess. With these assumptions, the total amount of air used is found to be $47.15 \mathrm{~kg} / \mathrm{hr}$ (Table 9).

Coal: The gas compressor (C-101) uses $387 \mathrm{~kW}$ of power. It is assumed that the fuel used for production of electricity is coal. Using the conversion factor $(1 \mathrm{~kW}-\mathrm{h}$ of electricity $=10000 \mathrm{Btu}$ fuel in power plant), the total amount of coal used on an hourly basis was calculated to be $14.69 \times 10^{6} \mathrm{MJ}$. Thus to provide $387 \mathrm{~kW}$ power for the compressor, the total amount of coal used on an hourly basis is $14.69 \times 10^{6} \mathrm{MJ}$.

Emissions/discharge data for CNT-FBR process: The carbon nanotubes produced by CNT-FBR process contain trace amounts of cobalt (II) chloride $\left(\mathrm{CoCl}_{2}\right)$ and molybdenum (II) chloride $\left(\mathrm{MoCl}_{2}\right)$ as impurity. In this study, we do not account for the entire life cycle of the carbon nanotubes. The scope of this study is from "Entry-to-Exit" for the particular process flow sheet in discussion. This does not include the usage and disposal phase of the products. Due to this, the impurities in the product are treated as a part of the final saleable product. However, the CNT-FBR process produces several other chemicals which include carbon dioxide, carbon monoxide, water, sodium hydroxide $(\mathrm{NaOH})$, cobalt (III) oxide $\left(\mathrm{Co}_{2} \mathrm{O}_{3}\right)$ and molybdenum oxide $\left(\mathrm{MoO}_{3}\right)$. In this section the detail of non--product
Table 9: Total air consumed in CNT-FBR process

Air Consumption

\begin{tabular}{llc}
\hline Unit & Material & Flow Rate $(\mathrm{Kg} / \mathrm{hr})$ \\
\hline T-203 & Air & 0.01 \\
Z-208 & $\mathrm{O}_{2}$ & 47.14 \\
& Total Air & 47.15 \\
\hline
\end{tabular}

Table 10: Input data for base case of CNT-PFR and CNT-FBR process

\begin{tabular}{llll}
\hline CNT-PFR Process & \multicolumn{2}{c}{ CNT-FBR Process } \\
\hline Component & Flow Rate $(\mathrm{kg} / \mathrm{hr})$ & Component & Flow Rate $(\mathrm{kg} / \mathrm{hr})$ \\
\hline Air & 1058 & Air & 47.15 \\
Water & 64239 & Water & 72355 \\
Component & Flow Rate $(\mathrm{kj} / \mathrm{hr})$ & Component & Flow Rate $(\mathrm{kj} / \mathrm{hr})$ \\
Natural Gas & 778 & Natural Gas & 980.42 \\
Coal & $4.01 \mathrm{E}+10$ & Coal & $1.47 \mathrm{E}+10$ \\
\hline
\end{tabular}

Table 11: Output data for base case of CNT-PFR and CNT-FBR process

\begin{tabular}{llllll}
\hline \multicolumn{2}{l}{ CNT-PFR Process } & \multicolumn{4}{l}{ CNT-FBR Process } \\
\hline Component & Flow Rate & Media of & Component & Flow Rate & Media of \\
\hline \multirow{2}{*}{$\mathrm{CO}_{2}$} & $(\mathrm{~kg} / \mathrm{hr})$ & Disposal & & $(\mathrm{kg} / \mathrm{hr})$ & Disposal \\
$\mathrm{H}_{2} \mathrm{O}$ & 2666 & Air & $\mathrm{CO}_{2}$ & 2727 & Air \\
$\mathrm{Fe}_{2} \mathrm{O}_{3}$ & 64239 & Water & $\mathrm{H}_{2} \mathrm{O}$ & 72355 & Water \\
& 256 & Soil & $\mathrm{Co}_{2} \mathrm{O}_{3}$ & 26 & Air \\
& & & $\mathrm{MoO}_{3}$ & 28 & Air \\
& & & $\mathrm{NaOH}$ & 228 & Soil \\
& & & $\mathrm{CO}$ & 349 & Air \\
& & & $\mathrm{H}_{2}$ & 25 & Air \\
\hline
\end{tabular}

outputs of CNT-FBR process are discussed. These include:

Carbon dioxide $\left(\mathbf{C O}_{2}\right)$ : The total amount of $\mathrm{CO}_{2}$ released by CNT-FBR process is $2727 \mathrm{~kg} / \mathrm{hr}$ by discharge valve (Z-209). This pure $\mathrm{CO}_{2}$ can be either released in the atmosphere or reused as a byproduct to be used as raw material for any economic process ${ }^{[7]}$.

Carbon monoxide (CO): The catalyst regeneration bed produces $349 \mathrm{~kg} / \mathrm{hr}$ of CO. It can have serious health impacts on humans when exposed to levels of $200 \mathrm{ppm}$ or higher for a long time. It may also contribute to global warming. On the other hand, it can be used for the production of methanol, aldehydes etc. Thus, CO can either be released in the atmosphere or reused as a raw material either in the same process or any other process $^{[11]}$.

Water $\left(\mathbf{H}_{2} \mathbf{O}\right)$ : The total amount of water released depends upon various scenarios discussed previously. If all the water is recycled, the net disposal would be zero. However, if nothing is recycled and is sent to the treatment facility then the net water discharged would be $72355 \mathrm{~kg} / \mathrm{hr}$.

Cobalt (III) oxide $\left(\mathrm{Co}_{2} \mathrm{O}_{3}\right)$ : The Centrifuge Separator (Z-203) produces $26 \mathrm{~kg} / \mathrm{hr}$ of Cobalt(III) Oxide. It is a non combustible black-grey crystalline powder which 
Am. J. Environ. Sci., 4 (5): 522-534, 2008

Table 12: Environmental impact data for base design of CNT-PFR and CNT-FBR Process

\begin{tabular}{llll}
\hline Impact category & Unit & CNT-PFR Process & CNT-FBR Process \\
\hline Global Warming & $\mathrm{CO}_{2}$ eq. & 6.29 & 5.82 \\
Acidification & $\mathrm{H}+$ moles eq. & 0.1570 & 0.0799 \\
HH Noncancer & toluene eq. & 0.0583 & 0.0695 \\
Smog & NOx eq. & 0.00252 & 0.00939 \\
HH Criteria Air-Mobile & PM2.5 eq. & 0.000421 & 0.000182 \\
HH Criteria Air-Point Source & PM2.5 eq. & 0.00040 & 0.00017 \\
Eutrophication & N eq. & 0.000102 & 0.0000621 \\
HH Cancer & benzene eq. & 0.0000559 & 0.0000644 \\
Ecotoxicity & 2,4-D eq. & 0.0000373 & 0.0000137 \\
\hline
\end{tabular}

Table 13: Environmental impact data for new design

\begin{tabular}{llll}
\hline Impact category & Unit & CNT-PFR Process & CNT-FBR Process \\
\hline Global Warming & $\mathrm{CO}_{2}$ eq. & 1.81 & 1.24 \\
Acidification & $\mathrm{H}+$ moles eq. & 0.157 & 0.0799 \\
HH Cancer & benzene eq. & 0.0000559 & 0.0000644 \\
HH Noncancer & toluene eq. & 0.0583 & 0.0695 \\
HH Criteria Air-Point Source & PM2.5 eq. & 0.00040 & 0.00017 \\
HH Criteria Air-Mobile & PM2.5 eq. & 0.000421 & 0.000182 \\
Eutrophication & N eq. & 0.0001020 & 0.0000621 \\
Ecotoxicity & 2,4-D eq. & 0.0000373 & 0.0000137 \\
Smog & NOx eq. & 0.00252 & 0.00154 \\
\hline
\end{tabular}

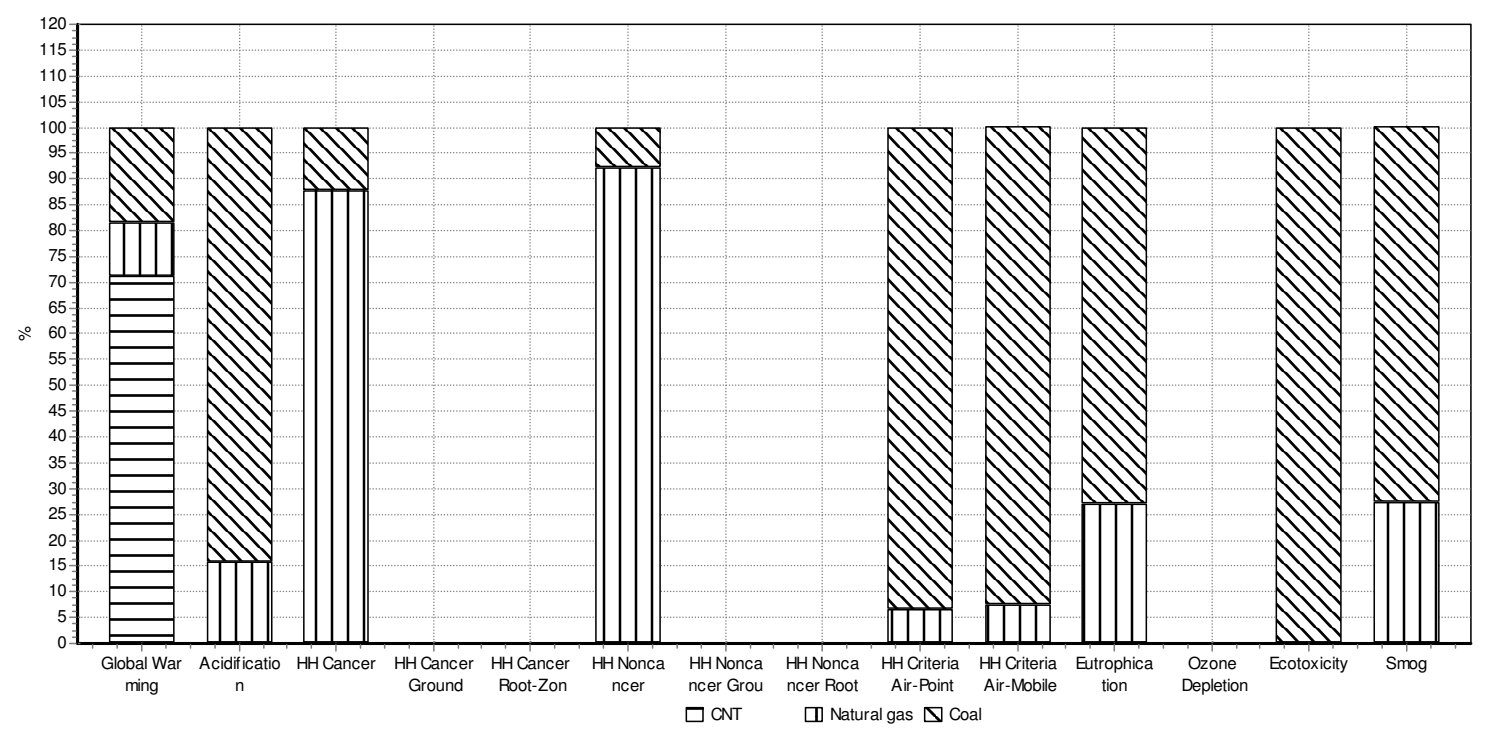

Fig. 3: Environmental impact of CNT-PFR process using base design

causes cough, sore throat and shortness of breath if inhaled. Ingestion may cause abdominal pain or nausea. Its exposure limit is $0.02 \mathrm{mg} / \mathrm{m}^{[3]}$. Although rigorous studies have not been conducted to check if $\mathrm{Co}_{2} \mathrm{O}_{3}$ is a human carcinogen, other cobalt compounds have been found to be carcinogenic. Thus, it can be considered as a potential human carcinogen. On the contrary, it can be used in ceramics for coloring or for extracting cobalt. Thus, this $\mathrm{Co}_{2} \mathrm{O}_{3}$ can be either disposed as a waste or can be reused as a resource by another process to recover Cobalt or may be used as it is.

Molybdenum oxide $\left(\mathbf{M o O}_{3}\right)$ : The effluent stream of the centrifuge separator (Z-203) produces $28 \mathrm{~kg} / \mathrm{hr}$ of molybdenum oxide. It is a white to off white powder and is considered to be a toxic material, which may cause severe distress, cramping, vomiting, and hypertension when taken in large doses. The OSHA Permissible Exposure Limit (PEL) for soluble 


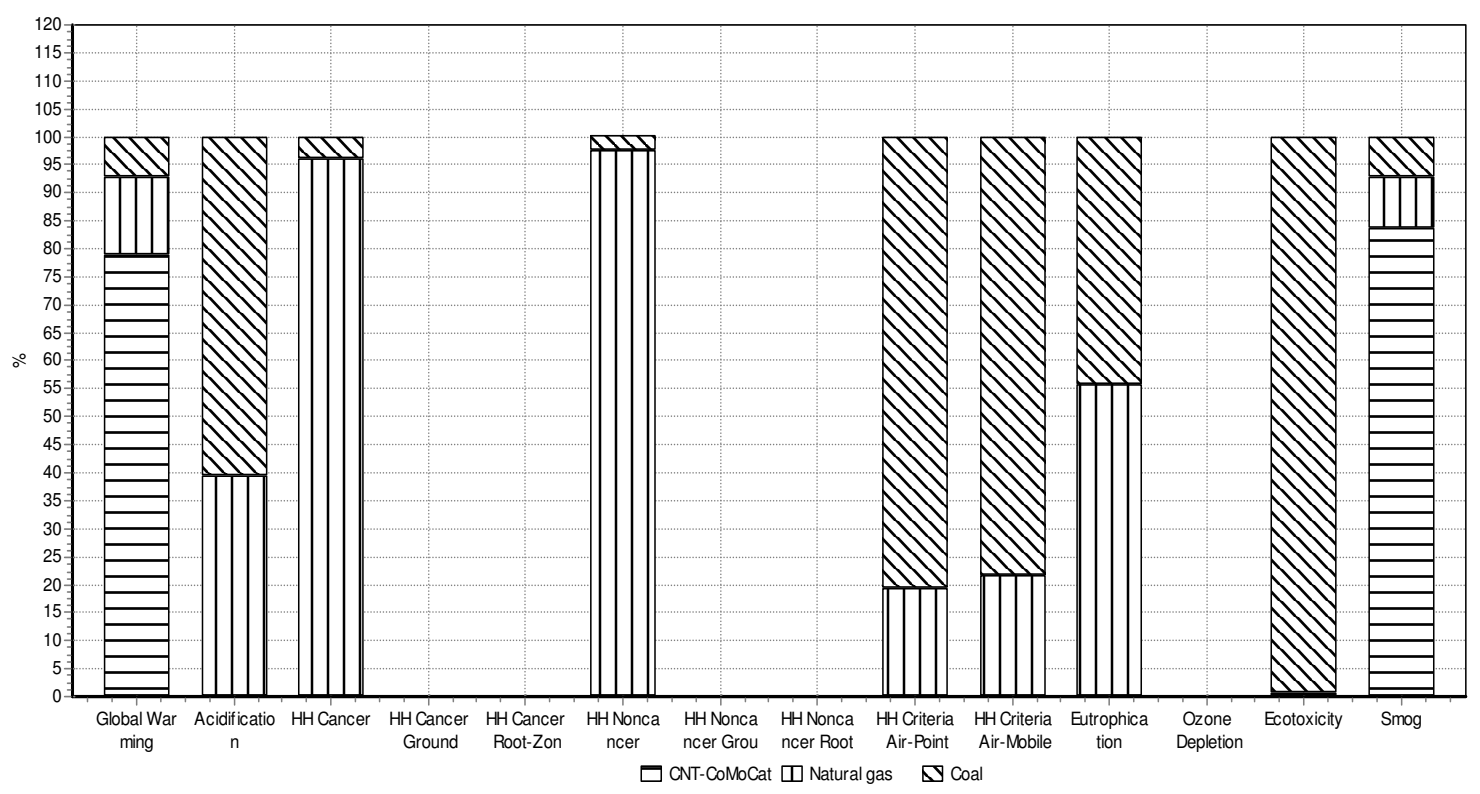

Fig. 4: Environmental impact of CNT-FBR process using base design

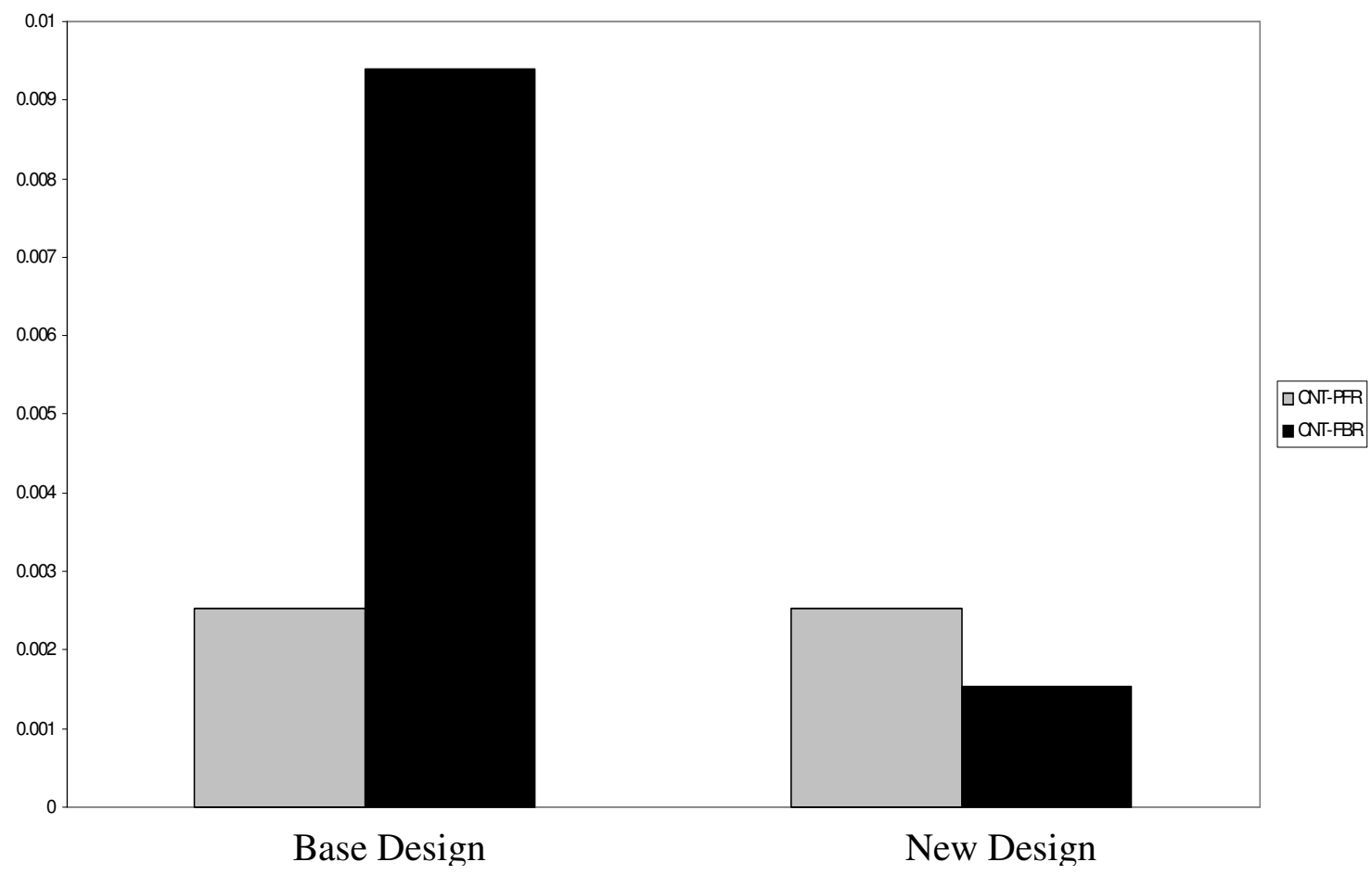

Fig. 5: Contribution of CNT-PFR and CNT-FBR process to smog formation in base design and new design

molybdenum compounds is $5 \mathrm{mg} / \mathrm{m}^{[3]}$ and for insoluble molybdenum compounds is $15 \mathrm{mg} / \mathrm{m}^{[3]}$. It is slightly soluble in water. It can be either disposed as a waste or can be reused as a resource by another process to recover molybdenum or may be used as it is. 
Am. J. Environ. Sci., 4 (5): 522-534, 2008

Table 14: Contribution of CNT-PFR and CNT-FBR Process to smog formation in base

\begin{tabular}{lll}
\hline \multicolumn{3}{l}{ Design and New Design } \\
\hline & Base & New \\
\hline CNT-PFR & 0.00252 & 0.00252 \\
CNT-FBR & 0.00939 & 0.00154 \\
\hline
\end{tabular}

Table 15: Contribution of CNT-PFR and CNT-FBR process to global warming in base

Design and New Design

\begin{tabular}{lll}
\hline & Base & New \\
\hline CNT-PFR & 6.29 & 1.81 \\
CNT-FBR & 5.82 & 1.24 \\
\hline
\end{tabular}

Sodium hydroxide (NaOH): The liquid-solid filter (Z204) produces $228 \mathrm{~kg} / \mathrm{hr}$ of sodium hydroxide. It is a strong base used in the chemical industry. It can be used to drive chemical reactions, neutralize acidic materials, as a neutralizing agent in petroleum refining etc. Sodium hydroxide solutions containing high concentrations of sodium hydroxide may cause chemical burns, permanent injury or scarring, and blindness. It would be best to reuse it for the same process if possible, or treat it as a by product and sell it after necessary treatment.

Hydrogen $\left(\mathbf{H}_{\mathbf{2}}\right)$ : The catalyst regeneration bed (Z-207) produces $25 \mathrm{~kg} / \mathrm{hr}$ of hydrogen. This comes out in a mixed stream with carbon monoxide. Since there is no toxicity data available for Hydrogen, this hydrogen can be either separated from the mixture or can be reused or disposed in the environment. However, since it is highly combustible, it should be handled with care.

Environmental impact assessment methodology: In order to assess the environmental impacts of these processes TRACI methodology is employed in SimaPro $7.0^{[12]}$. TRACI stands for The Tool for the Reduction and Assessment of Chemical and other environmental Impacts (TRACI) developed by USEPA. It consists of a modular set of impact assessment methods that provide the most up-to-date impact assessment for US based products/processes. It facilitates environmental comparison of products and process alternatives for internal environmental decision-making ${ }^{[13]}$. TRACI first classifies the resources and releases into various impact categories and then characterizes them based on the impact categories using their characterization value. The characterization value quantifies the extent of harm that a stressor can cause in a particular impact category ${ }^{[13]}$. TRACI characterizes various stressors into the following impact categories:
Ozone depletion: It accounts for the depletion of the protective ozone layer in the earth's stratosphere due to harmful emissions like chlorofluorocarbons, halons, etc. The contribution in this impact category is measured as, Ozone Depletion Index $=\sum_{i} e_{i} \times O D P_{i}$

where, $e_{i}$ is the emission (in $\mathrm{kg}$ ) of substance $\mathrm{i}$ and $\mathrm{ODP}_{\mathrm{i}}$ is the ozone depletion potential of substance $i$. The ozone depletion index is measured in terms of CFC-11 equivalents / $\mathrm{kg}$ emission.

Global warming: It refers to the change in earth's climate due to the build-up of chemicals that trap heat from the sunlight like carbon dioxide, methane, nitrous oxide, etc. The contribution towards global warming is measured as,

Global Warming Index $=\sum_{i} e_{i} \times G W P_{i}$,

where $e_{i}$ is the emission (in $\mathrm{kg}$ ) of substance $\mathrm{i}$ and $G P_{i}$ is the global warming potential of substance $i$. The global warming index is measured in terms of $\mathrm{CO}_{2}$ equivalent / $\mathrm{kg}$ emission.

Acidification: This includes the chemicals that increase the acidity of water and soil systems by releasing $\left[\mathrm{H}^{+}\right]$ or equivalents. TRACI uses the emission data of $\mathrm{NO}_{\mathrm{x}}$ and $\mathrm{SO}_{2}$ for this. The contribution to this impact category is expressed in $\left[\mathrm{H}^{+}\right]$moles equivalent deposition/ kg emission.

Eutrophication: Eutrophication is a phenomenon in an aquatic ecosystem where high nutrient concentration stimulates algae growth. The contribution in this impact category is measured in terms of nitrogen equivalents released / $\mathrm{kg}$ of emission.

Photochemical smog: The characterization value associated with this impact category accounts for the formation of ozone molecules in troposphere which is influenced by the ambient concentrations of nitrogen oxides $\left(\mathrm{NO}_{\mathrm{x}}\right)$ and volatile organic compounds (VOCs) The contribution in this impact category is measured in terms of $\mathrm{NO}_{\mathrm{x}}$ or equivalent.

Human health cancer and non-cancer: This involves reliable ranking and relative comparisons of a large number of chemicals in terms of their potential to cause toxicological impacts. The contribution for Human Health Cancer is measured in terms of benzene equivalents released $/ \mathrm{kg}$ of emission. The contribution for Human Health Non-Cancer is measured in terms of toluene equivalents released $/ \mathrm{kg}$ of emission. 
Human health criteria: This accounts for measuring the ambient concentrations of particulate matter found to be associated with changes in background rates of chronic and acute respiratory systems as well as the mortality rate. The contribution to this impact category is given in terms of DALYs(Disability Adjusted Life Years) / tonne of emission.

Eco-toxicity: It uses Ecological Toxicity Potential (ETP) to quantitatively measure the ecological harm of a unit quantity of chemical released in the environment. The contribution to this impact category is measured in terms of 2,4-Dichloro-phenoxyacetic acid equivalents released $/ \mathrm{kg}$ of emission.

Fossil fuel use: The contribution in this impact category is calculated using, Fossil Fuel Index = $\sum_{i} N_{i} \times F_{i}$

where $\mathrm{N}_{\mathrm{i}}$ is the increase in energy input requirements per unit of consumption of fuel $i$ and $F_{i}$ is the consumption of fuel $\mathrm{i}$ per unit of product. The contribution in this impact category is measured in MJ of surplus energy per MJ of extracted energy in the process.

Land use: The contribution in this category is calculated using

Land Use Index $=\sum_{i} A_{i} \times\left(T \& E_{i}\right) / C A_{i}$

where, $A_{i}$ is the human activity per functional unit of the product, $T \& E_{i}$ is the $T \& E$ species count for the county and $\mathrm{CA}_{\mathrm{i}}$ is the area of the county under consideration.

Water use: This impact category of captures the significant use of water in areas of low availability. The contribution in this impact category is measured in gallons. TRACI has been developed to provide the most up-to-date possible treatment of impact categories for North America.

In this study, we conduct a comparative environmental impact analysis for two case studies developed for the CNT-PFR process and CNT-FBR process. The first case study - "Base Design" uses the process data as it is. It assumes that there is no recycle or reuse or resources in both these processes. The results for the Base Design are calculated by directly using the input-output data from the flowsheet. The second case study - "New Design" assumes that all the material that is being generate apart from the main product is a by-product and can be used to generate revenue for each process as it can not only be sold to another manufacturer but also cuts down the disposal/treatment cost or penalty that the company may have to pay.

Case study 1. Environmental impact calculation for base design: In the base design of the two processes, it is assumed that none of the resources are recycled. All the outputs coming out of the system are treated as emissions. It is assumed that the outlet streams, except the main product stream are disposed to the environment. The natural resource consumption data and the output data for the CNT-PFR process and CNTFBR process for the base design is presented in Table 10 and 11 respectively. A comprehensive illustration of contribution of CNT-PFR towards each impact category is given in Fig. 3. A similar illustration for CNT-FBR process is given in Fig. 4.

The results generated by using TRACI for the base design are tabulated in Table 12. The contribution of CNT-PFR process towards global warming, acidification, human health criteria (Air: Point Source and Mobile), eutrophication and ecotoxicity is much higher than that of CNT-FBR process. On the other hand, the contribution of CNT-FBR process is higher towards human health non-cancer and smog formation. Thus there is a tradeoff between various categories. However, in terms of base design, the performance of CNT-FBR process is better as its contribution in most of the categories is much lower.

Case study 2. Environmental impact calculation for new design: The new design scheme is developed based on the principle that no product is waste. All the outlets coming from each process are treated as a byproduct. As mentioned previously, each compound can be reused as it is or after processing. Thus it makes no sense to dispose them all into the environment. For both processes, water is recycled. As a result of which, there is not net consumption of water except for the minimal losses. We do no account for that in the current study. The consumption of natural resources remains the same for both processes except for water consumption which is recycled completely.

The environmental impact data for each of these designs is listed in Table 13. A comparison of these impact values shows that the impact of both processes has reduced manifold in terms of contributions towards global warming and smog formation (Tab 14 and 15). Another interesting observation is that the contribution of CNT-PFR process towards smog formation exceeds that of CNT-FBR process in the new design scheme. 


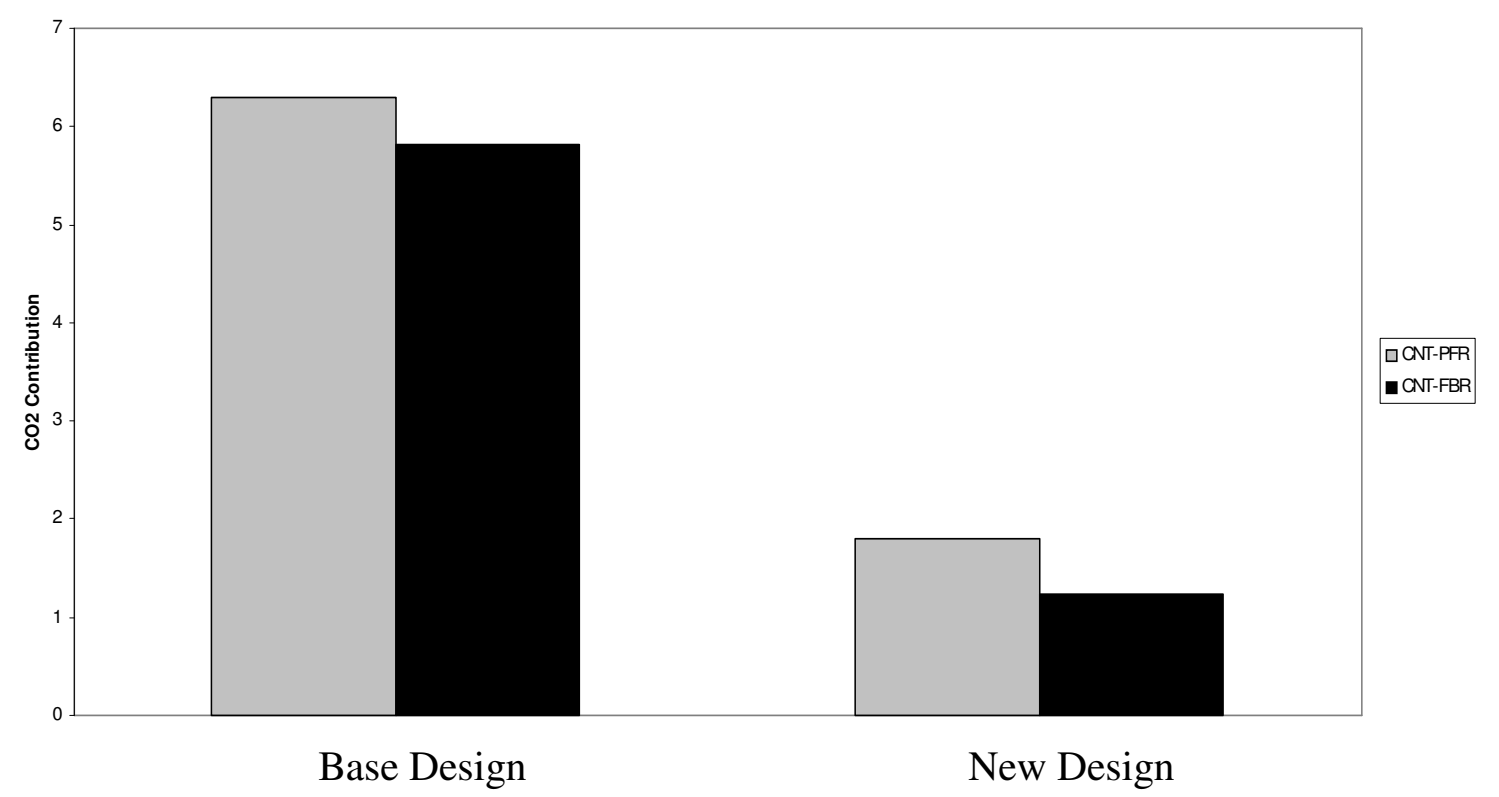

Fig. 6: Contribution of CNT-PFR and CNT-FBR process to global warming in base design and new design

This is illustrated in Fig. 5 and 6. This again proves that depending upon the waste disposal scenario, the performance of each process may change significantly.

\section{DISCUSSION}

In this work, an attempt was made to demonstrate the utility of conducting a comprehensive environmental impact assessment of carbon nanotubes production facility. These processes were defined in the software SimaPro 7.0. In SimaPro, each new product/process is defined as a combination of predefined products/processes available in it. For the current case study, we have used the "Carbon Fiber" to represent the carbon nanotubes. This is the product that could most closely represent the carbon nanotubes. The drawback of such an approach is that since it selects a predefined module, it automatically adds the corresponding consumptions and emissions that have been defined for the default process. All the other emissions/consumptions we define are an addition to it. In our case, it does not make much difference because we are doing a comparative analysis. Since we use Carbon Fiber production process as the basis for both CNT-PFR and CNT-FBR process, the default consumptions defined for Carbon Fiber Production process cancel each other.

As shown in the results, the environmental performances of each process may change drastically depending upon whether the non-product outputs are treated as a by-product or waste. It was observed that from the base design to the new design, the emission of carbon dioxide, carbon monoxide and hydrogen is reduced as we treat them as by-products in new design.

However, another important observation is that the performance of these processes has switched from base design to the new design in terms of its contribution towards smog formation. This shows that a comprehensive environmental impact assessment may produce vital data about the performance of each process in terms of various environmental impact categories. This comes in handy when designing a process for a particular region where one impact category is more crucial than others.

In the input/output data of the CNT-FBR process and CNT-PFR process, it was observed that they generate a lot of unconventional effluents like $\mathrm{Fe}_{2} \mathrm{O}_{3}$, $\mathrm{Co}_{2} \mathrm{O}_{3}, \mathrm{MoO}_{3}, \mathrm{NaOH}$ during the manufacturing phase. Eventually, they may also release $\mathrm{FeCl}_{2}, \mathrm{CoCl}_{2}$ and $\mathrm{MoCl}_{2}$ along with carbon during the usage and disposal phase of CNT. It was found that the available databases in SimaPro could not account for the environmental impact of these chemicals on the environment (emission in air, water or soil). This was mainly due to the lack of characterization values for these particular chemicals for different discharge media. With evolving technologies and upcoming state-of-the-art processes being developed to produce new and better products, it 
is required to keep up with the corresponding emissions data in terms of their characterization factors for various discharge media. This is crucial in order to have a better understanding of the short-term as well as longterm impacts of new processes on environmental sustainability.

\section{ACKNOWLEDGEMENT}

This work is in-part supported by the National Science Foundation under Grant CTS-0407494, the Texas Advanced Technology Program under Grant No. 003581-0044-2003, the Gulf Coast Hazardous Substance Research Center and the Texas Hazardous Waste Research Center.

\section{REFERENCES}

1. Agboola, 2005. Development and Model Formulation of Scalable Carbon NanotubeProcesses: HiPCO and CoMoCAT Process Models, M.S. thesis, Louisiana State University, Baton Rouge, LA.

2. Bronikowski, M.J., P.A. Willis, T.D. Colbert, K.A. Smith and R.E. Smalley, 2001. Gas-phase Production of Carbon Single-walled nanotubes from carbon monoxide via the HiPCO Process: A parametric study. J. Vacuum Sci. Tech. A., 19: 1800-1805.

3. Nikolaev, P., 2004. Gas-Phase Production of Single Walled Cabron nanotubes from Carbon Monoxide: A review of the HiPCO Process. J. Nano Sci. and Nano Tech., 4: 307-316.

4. Davis, V.A., 2005. Carbon Nano Tech. Laboratory, Chemical Engineering Department, Rice University. Private Communication.
5. Chiang, I.W., B.E. Brinson, R.E. Smalley, J.L. Margrave and R.H. Hauge, 2001. Purification and Characterization of Single-Wall Carbon Nanotubes. J. Phys. Chem. B., 105: 1157-1161. Meyyappan, W. and D. Srivasta, 2003. Handbook of Nano Sci. Engin. and Tech., 18: 1-26.

7. Xu, A., R.W. Pike, S. Indala, F.C. Knopf, C.L. Yaws and J.R. Hopper, 2005. Development and integration of new processes consuming carbon dioxide in multi-plant chemical complexes. Clean Technology and Environmental Policy, 7: 97-115.

8. Greenwood, N.N. and A. Earnshaw, 1984. Chemistry of the Elements. Pergamon Press.

9. Resasco, D.E., W.E. Alvarez, F. Pompeo, L. Balzano, J.E. Herrera, B. Kitiyanan and A. Borgna, 2001. A scalable process for production of singlewalled carbon nanotubes by catalytic disproportionation of $\mathrm{CO}$ on a solid catalyst. J. Nanoparticle Res., 00, 1-6.

10. Pisan, C., S. Chavadej, B. Kitiyana, J.F. Scamehorn and D.E. Resasco, 2004. Separation of Single-Wall Carbon Nanotubes from Silica by Froth Flotation Technique AIChE Annual Meeting, Indianapolis, IN.

11. Holleman, A.F. and E. Wiberg, 2001. Inorganic Chemistry, Academic Press: San Diego.

12. Pre Consultants. Sima. Pro. 7.0, LCA Software: User Manual. Netherlands. http: // www. pre. nl/ down load/ manuals /Sima Pro7 Introduction To LCA. pdf

13. Bare, J.C., G.A. Norris, D.W. Pennington and T. McKone, 2002. TRACI: The tool for the reduction and assessment of chemical and other environmental impacts. J. Indust. Ecol., 6: 49-78. 